\title{
The effect of an exhaustive aerobic, anaerobic and resistance exercise on serotonin, beta-endorphin and BDNF in students
}

\author{
Sharifi M. ${ }^{A B C D E}$, Hamedinia M.R. ${ }^{A B C D E}$, Hosseini-Kakhak S.A. ${ }^{A B C D E}$ \\ Department of Sport Physiology, Faculty of Sport Sciences, Hakim Sabzevari University, Sabzevar, Iran
}

Authors' Contribution: A - Study design; B - Data collection; C - Statistical analysis; D - Manuscript Preparation; E - Funds Collection.

\begin{abstract}
Purpose: $\quad$ Sport exercises play a major role in many hormonal factors which related to happiness in human. Therefore, the short-term effects of three anaerobic, aerobic and resistance exercises on (BDNF) and hormones related to happiness such as serotonin and beta-endorphin has been studied in young men in this research.

Material: $\quad$ Thirty-two students (19 to 25 years old) who did not have regular physical activity were randomly divided into four groups, after the subjects were eaten the same breakfast, the blood of them were taken before and after the various short aerobic exercises (Exhaustive exercise with $70 \%$ of maximum heart rate) and anaerobic (Exhaustive exercise with maximum intensity) and exhaustive resistance exercise (with 8 stations). Control group did not practice any activity. Specific kits and ELISA method have been used to determine their values. Data were analyzed using ANOVAand ANCOVA method at a significant level of $5 \%$.

Results: $\quad$ Beta-endorphins showed a significant increase in resistance and aerobic training sessions compared to control group. However, serotonin and BDNF had a significant intra-group change in the aerobic group.

Conclusions: It seems that aerobic exercises are the best practice for increasing some of the hormones associated with happiness. Keywords: $\quad$ BDNF, Beta-endorphin, Serotonin, Aerobic Exercise, Anaerobic Exercise, Resistance Exercise.
\end{abstract}

\section{Introduction}

Sport is one of the most prevalent conditions for challenging the human physiological systems. A more contemporary label which has been often applied to these exercises induced changes, is the "runner's high." The runner's high has been described subjectively as pure happiness, elation, a feeling of unity with one's self and/ or nature, endless peacefulness, inner harmony, boundless energy, and a reduction in pain sensation [1]. Up to date, Brain-Derived Neurotrophic Factor (BDNF), a member of the neurotrophin family which is promoting neuronal survival and proliferation, has been described as one of the best potential candidate molecules that plays a role in exercise-induced antidepressant effects [2]. In general, this neurotrophic factor has been found in the brain and peripheral nerves and it plays an important role in protection and production of neurons [3]. Sport activity has been shown to increase the secretion of BDNF in protein and mRNA levels of a Mice hippocampus and it provides evidence to claim that sport activity has a potential to increase neurotrophins in humans [4]. There is contradictory information about the impact of endurance and strength of training on BDNF values. Probably, these three training methods can affect the synthesis and BDNF release. However, it is not clear that this system will respond to the anaerobic and circuit strength exercises. Besides, no research has yet investigated the effects of various training methods on this system during a training period.

Serotonin or 5-hydroxytryptamine is a monoamine neurotransmitter that plays a significant role in regulating the neuro-hormonal system, modifying the mood, appetite, joy, sleep, physiological activities, and effective cognitive activities in learning and memory [5]. Serotonin has been synthesized in an enzyme pathway from the tryptophan amino acid. This mediator has been also known as the (c) Sharifi M., Hamedinia M.R., Hosseini-Kakhak S.A., 2018 doi:10.15561/20755279.2018.0507 hormone of happiness. The density of tryptophan in the brain and hence the synthesis rate of 5-hydroxytryptophan depends on the density of free tryptophan in plasma and the density of large non-polar amino acids that pass through the blood to the brain via transfer mechanisms that are similar to tryptophan [6]. The results of various studies have showed that aerobic exercises such as jogging, running, cycling and swimming seemed to affect serotonin secretion in humans significantly [7]. The exact mechanism of this function is still unclear, but it is clear that aerobic exercise has been improved individuals' mood as a result of increase in serotonin level [7]. Information on acute changes at serotonin levels is still unclear because of exercising. [8]. Researches on strength training suggest that there is no change in serotonin levels in most cases $[9,10]$. The level of serotonin depends on the intensity and duration of the exercise, the exercise protocol and the elapsed time after the last training session that samples were taken [11]. Endorphins or hormones of happiness have been released in every physical activity; endorphin is secreted by the anterior pituitary gland in response to exercise; physical and psychological stress [12]. The most important of all hormones related to happiness that is betaendorphin and it is released in the blood. Beta-endorphin has been released from hypothalamic neurons in the spinal cord and brain, and from the pituitary gland. The behavioral effect of beta-endorphin has been determined by brain growth function and possibly by hypothalamic neurons, which are the largest source of beta-endorphin [12]. Various research results show that different aerobic, anaerobic, and strength training will result in serum betaendorphins increase $[13,14]$. Various studies have shown that beta-endorphin responds differently to the intensity of exercises and it depends on the various features of both aspects, i.e. individuals (e.g., health status, preparation level), and type of exercise [15]. Researches on exercise training and its effect on endorphin density 
have contradictory results. Therefore a research that has been conducted on various types of training programs and their effects on endorphin density in plasma can provide valuable information to the researchers.

The results of most short-term studies of betaendorphins show that higher-intensity exercises have been increased the amount of $\beta$-endorphin in proportion to pre-exercise state, the results of this type of research on serotonin levels appear to be influenced by the training program and the results are different according to training method, and regarding BDNF the results are contradictory that is mostly related to training method and the specimens. Therefore, further research is needed to investigate the features of hormone responses which are related to happiness, such as serotonin, beta-endorphin, and BDNF, in relation to the physical activity, and especially in relation to relevant and important factors such as duration and intensity of the physical activity, type of the activity, gender, and weight of the participated specimens in the study that can have a significant effect on research results. Therefore, the purpose of this study is to evaluate the short-term effects of three anaerobic, aerobic and strength training methods on serotonin, betaendogenous and BDNF hormones in young men.

\section{Material and Methods}

Participants.

The study population included boy students aged 1925 in Babol who did not regularly participate in sports activities. 32 of the participants were volunteers. The inclusion criteria were age range of 19-25, the willingness to participate in the study, no smoking, no use of notorious or mood enhancing supplements, physical and mental health and no diseases in specimens' medical history. Exclusion criteria were non-compliance with the training protocol and inability to collect the information sought by the researchers.

\section{Research Design.}

The present research is semi-experimental. The research and methodology and possible dangers during the training were described to the specimens in one session, and then the informed consent was taken from all the specimens. All ethical principles were followed during the training process; code of ethics for this study was obtained from Sabzevar University of Medical Sciences under the following number (IR.MEDSAB. REC.1395.127); specimens randomly divided into four groups of aerobic, anaerobic, strength training and control groups. The height, weight and the fat percentage of the specimens were collected in the first session. One hour after having breakfast, that was identical for all (included juice and breakfast cake with $250 \mathrm{cal}$ ), all specimens according to the classified groups performed in a training session (anaerobic, aerobic, or strength training). 5Cc of blood were taken in two phases of before and after shortterm activity from the cephalic vein of the right arm in the resting position, then immediately poured into the test tubes that contained EDTA (anti-coagulation agent) and centrifuged for 3 minutes at 10,000rpmand the isolated plasma was stored at $-20^{\circ} \mathrm{C}$ till the variables were measured.

Each set consists of 30,60 and 90 meters running, respectively.

Statistical Analysis.

Analyzes of serotonin, $\beta$-endorphin and BDNF hormone densities were measured by ELISA method. To measure $\beta$-endorphin, serotonin and BDNF, plasma density ELISA was used; it is produced by EASTBIOPHARM Company in China, with a sensitivity of $2.59 \mathrm{ng} / 1,1.22 \mathrm{ng} /$ $\mathrm{ml}$, and $0.01 \mathrm{ng} / \mathrm{ml}$. Finally, all data were analyzed using SPSS software version 20. Shapiro-Wilk test was used to determine the normality of the data. After assuring the data were normal, ANCOVA, ANOVA and dependent t-test were used to compare the data. Alpha is assumed 0.05 .

\section{Results}

According to the Shapiro-Wilk test, it was found that all variables data in the research groups are of normal distribution. Table 4 shows the anthropometric characteristics of the subjects. One session of anaerobic exercise, aerobic exercise and strength training had no significant effect on serotonin and plasma BDNF levels in proportion to the control group and there was no

Table 1. Aerobic exercise program for one session

\begin{tabular}{lllll}
\hline Type of exercise & Intensity(Maximum heart rate) & Time sets & Rest between sets & Number of sets \\
\hline Running & $70 \% \mathrm{HR}$ max & 3 minutes & 1 minutes & Until exhaustion \\
\hline
\end{tabular}

Table 2. Anaerobic exercise program for one session

\begin{tabular}{lllll}
\hline Type of exercise & Intensity & Practical Distances $(\mathrm{m})$ & Rest between sets & Number of sets \\
\hline Running & Maximum & $30,60,90$ & $30 \mathrm{~s}$ to $1 \mathrm{~min}$ & Until exhaustion \\
\hline
\end{tabular}

Table 3. A strength circuit training program for one session

\begin{tabular}{lllll}
\hline Type of exercise & Number of stations & Number of repetitions & Rest between stations & Number of sets \\
\hline Resistance & 8 & $8-12$ & 1 to 2 min & Until exhaustion \\
\hline
\end{tabular}


significant difference between the groups in this regard. However, one aerobic exercise session has significantly increased plasma beta-endorphin in proportion to control group. One anaerobic exercise session had no significant effect on the same index. Nevertheless, intra-group changes were significant in this group. In the aerobic group, a significant change was observed in serotonin and BDNF level in pre-exercise group (Table5).

\section{Discussion}

One session of anaerobic, aerobic and strength training had no significant effect on serotonin and plasma BDNF and there was no significant difference between the groups in this regard. However, one session of aerobic exercise has significantly increased plasma betaendorphin in proportion to the control group, while one session of anaerobic exercise did not apply the same effect in proportion to the control group. Nevertheless aerobic exercises led to a significant increase in intragroup serotonin and BDNF compared to the pre-exercise state.

In the present study, one session of aerobic and strength training has significantly increased plasma betaendorphin in proportion to control group; while one anaerobic exercise session had no significant effect on the same index. In various studies that have investigated the effect of short-term strength training on beta-endorphin, it was observed that these exercises led to an increase in the serum beta-endorphin levels $[13,14]$ that is consistent with the same study results. Variation in betaendorphin levels during strength training may be related to the exercise protocol (intensity, repetition, and breaks between the sets) [13].

Multiple research results have showed that various short-term aerobic exercises by professional and amateur individuals with an intensity of $90-60 \%$ of maximum oxygen would result in a significant increase in the plasma beta-endorphins levels [16] that are consistent with aerobic exercise results that are in the present study. The beta-endorphin secretion depends on the intensity and volume of both aerobic and anaerobic exercise [17]. In the present study, the intensity of exercise was at maximum but since the duration of the exercise was optional and depended on the physical capacity of the individuals until exhaustion, therefore, they did not finish the exercise at the same time. On the other hand, Bandar et al. (2007) have stated that duration of the exercise has been more effective in beta-endorphin secretion than intensity of the exercise [18], consistent with Bandar et al., since in the present study, anaerobic exercises were performed at maximum intensity, they were done in shorter time frame than aerobic exercises; and on the contrary, since aerobic exercises were done with less intensity, they were performed in longer time frame than anaerobic exercises. Therefore, these anaerobic exercises did not increase $\beta$-endorphins. De Luigi et al. (2003) have showed that

Table 4. Anthropometric characteristics of subjects

\begin{tabular}{lllll}
\hline Group/Parameter & Height $(\mathrm{cm})$ & Age $($ year) & Fat Body percentage & Weight(Kg) \\
\hline Control group & $181.12 \pm 2.79$ & $21 \pm 1.19$ & $20.51 \pm 6.81$ & $78.87 \pm 11.88$ \\
Anaerobic group & $182.12 \pm 7.92$ & $21.12 \pm 1.72$ & $17.62 \pm 7.14$ & $72.88 \pm 20.27$ \\
Aerobic group & $179 \pm 7.17$ & $20.27 \pm 1.4$ & $15.64 \pm 6.04$ & $68.25 \pm 12.89$ \\
Resistance group & $180 \pm 11.2$ & $20.12 \pm 1.55$ & $22.67 \pm 6.15$ & $85.11 \pm 22.29$ \\
P & 0.88 & 0.48 & 0.1 & 0.2 \\
\hline
\end{tabular}

Table 5. Statistics related to the happiness mediators

\begin{tabular}{|c|c|c|c|c|c|}
\hline Parameter & Group & $\begin{array}{l}\text { Before } \\
\text { Exercises }\end{array}$ & After Exercises & P of Intergroup & P of Out of group \\
\hline \multirow{4}{*}{$\begin{array}{l}\text { Serotonin } \\
(\mathrm{ng} / \mathrm{ml})\end{array}$} & Control group & $82.48 \pm 7.21$ & $86.84 \pm 15.81$ & 0.46 & \multirow{4}{*}{0.26} \\
\hline & Anaerobic group & $83.14 \pm 21.67$ & $95.74 \pm 28.53$ & 0.28 & \\
\hline & Aerobic group & $64.43 \pm 14.24$ & $78.09 \pm 24.07$ & 0.03 & \\
\hline & Resistance group & $61.06 \pm 23.92$ & $70.22 \pm 23.47$ & 0.16 & \\
\hline \multirow{4}{*}{$\begin{array}{l}\text { Beta-Endorphin } \\
\text { (ng/L) }\end{array}$} & Control group & $141.08 \pm 67.86$ & $142.08 \pm 77.86$ & 0.29 & \\
\hline & Anaerobic group & $157.47 \pm 91.50$ & $175.47 \pm 91.50$ & 0.27 & \multirow{3}{*}{0.03} \\
\hline & Aerobic group & $195.66 \pm 104.5$ & $237.81 \pm 105.54$ & 0.007 & \\
\hline & Resistance group & $245.26 \pm 99.31$ & $276.39 \pm 103.21$ & 0.008 & \\
\hline \multirow{4}{*}{$\begin{array}{l}\text { BDNF } \\
(\mathrm{ng} / \mathrm{ml})\end{array}$} & Control group & $1.25 \pm 0.39$ & $1.24 \pm 0.35$ & 0.88 & \\
\hline & Anaerobic group & $1.08 \pm 0.31$ & $1.53 \pm 0.95$ & 0.26 & \multirow{3}{*}{0.63} \\
\hline & Aerobic group & $1.23 \pm 0.15$ & $1.38 \pm 0.31$ & 0.001 & \\
\hline & Resistance group & $0.97 \pm 0.52$ & $1.17 \pm 0.44$ & 0.21 & \\
\hline
\end{tabular}


an anaerobic exercise session on 18 male athletes did not increase serum beta-endorphin level [19], and it is consistent with the same study results. Octdalen et al. (2001) have stated that physical activity causes acidosis and as a result reduces blood $\mathrm{PH}$ in the body. This will activate the hypothalamus-pituitary axis and will result in the secretion of corticoliberin. Corticoliberin has been directly poured from the hypothalamus into the pituitary gland and corticotrophin and ACTH have been released by the pituitary. The beta-endorphin secretion from the anterior pituitary is associated with ACTH secretion, thereby increasing the production and secretion of $\beta$-endorphins from the pituitary [20]. Moreover, by binding to receptors, beta-endorphin keeps potassium channels open and calcium channels close, that leading to hypoglycemia, and this phenomenon provides the conditions for beta-endorphin production [21].On the other hand, the physical activity in hypoxic condition increases beta-endorphin secretion [22].

The present study has showed that three training groups during one sedation session could not result in a significant increase in serotonin level compared to the control group; although aerobic exercises will led to significant intra-group changes. Zhao et al. (2015) have showed that aerobic exercise with an intensity of 65 $70 \%$ of maximum heart rate did not significantly increase serotonin [23] that is consistent with the results of the same study. Shaykh al-Islam and Salavati (2011) in a study on young men have showed that accession of acute strength training with a small-to-large muscle training protocol led to a significant increase in serotonin, that is not consistent with the present study results; however, the large-to-small training protocol did not result in a significant increase in serotonin that is consistent with the present study results [24]. In the present study, one movement has been considered for the upper trunk and one movement for the lower trunk, respectively. Sharifi et al. (2012) have showed that a training session with Bruce instructions up to fatigue limit resulted in a significant increase in serotonin levels immediately after exercise that is not consistent with the results of the present study [7]. To justify the differences, we can assert that serotonin levels depend on the exercise intensity, duration, protocol, and the elapsed time after the last training session that samples have been taken [11]. As stated, in this study, the plasma levels of BDNF has been increased after three training methods but that was not significant in any of the groups compared to the control group, although there was a significant intra-group difference which has been observed in aerobic exercises. Curie et al. (2010) in a study on 16 young men have showed that strength training session did not significantly change plasma BDNF density; he suggested that the type of exercise program could be a determinant factor of BDNF change in blood circulation [25]. Of course, the results are consistent with the same study results. Several studies that examined short-term moderate-intensity training have showed that this type of exercise will led to an increase in instability in serum BDNF levels that does not have significant implications [26], and it is consistent with the results of the present study. Different results of studies that examine the effect of training can be attributed to the type, duration, and intensity of the training [25]. Peko et al. (2014) have observed that epinephrine has been increased in endurance exercises and intense periodic training; however, epinephrine increase is retained for one hour after endurance, while the same was not observed in the periodic training group. Regarding the maintenance of epinephrine increase for an hour after endurance exercise and cortisol increase in response to severe periodic training, it can be argued that endurance exercises is more proper to increase BDNF than intense periodic training. [27]. BDNF levels are expected to increase regarding the use of muscles in strength training to produce maximum force. [25]. This viewpoint has been supported by reports that BDNF expression is increased in response to skeletal muscle contraction. [28]. It has been suggested that the sources of BDNF are the neurons between the skeletal muscles [25].On the other hand, Matthias et al. (2009) have showed that although BDNF is produced by muscle, it cannot be transmitted to the bloodstream [29]. It seems in strength training, this is one of the main reasons for the absence of significant increase. On the other hand, Hinen et al. (2015) have argued that BDNF levels were adjusted during aerobic exercise by age, gender, and genetics [30] that could justify these differences in aerobic exercise.

\section{Conclusions}

The results of this study have been shown that the increase of internal factors leads to euphoria and feeling of happiness in human beings that seems to be different according to the type of exercise. Factors such as betaendorphin have been significantly increased after acute strength training and aerobic exercise sessions, while serotonin and BDNF did not significantly increase. Aerobic exercises seem to be the best type of exercise in increasing some hormones which are relevant to joy. With aerobic, anaerobic, and strength training, you can increase joy with respect to the duration and intensity of the exercise but this behavior is not influenced by some hormones alone and many factors affect this behavior.

\section{Acknowledgments}

I announce my appreciation to those who helped us in conduction of this research, especially the Physical Education Department of Babol Azad University.

\section{Ethical Approval}

All ethical principles were observed during the training process. Code of ethics for this study was obtained from Sabzevar University of Medical Sciences under the following number of IR.MEDSAB.REC.1395.127.

\section{Conflict of Interests}

No conflicts of interest have been stated by the authors. 


\section{References}

1. Dietrich A, McDaniel W. Endocannabinoids and exercise. British Journal of Sports Medicine. 2004;38(5):536-541.

2. Heyman E, Gamelin F-X, Goekint M, Piscitelli F, Roelands B, Leclair E, et al. Intense exercise increases circulating endocannabinoid and BDNF levels in humans - possible implications for reward and depression. Psychoneuroendocrinology. 2012;37(6):844-851.

3. Goekint M, Roelands B, De Pauw K, Knaepen K, Bos I, Meeusen R. Does a period of detraining cause a decrease in serum brain-derived neurotrophic factor? Neuroscience letters. 2010;486(3):146-149.

4. Cotman CW, Berchtold NC, Christie L-A. Exercise builds brain health: key roles of growth factor cascades and inflammation. Trends in neurosciences. 2007;30(9):464-472.

5. Hassan EA-H, Amin MA. Pilates Exercises influence on the serotonin hormone, some physical variables and the depression degree in battered women. World Journal of Sport Sciences. 2011;5(2):89-100.

6. Pardridge W, Connor J, Crawford I, Oldendorf W. Pekmeability changes in the blood-brain barrier: causes and consequences. CRC critical reviews in toxicology. 1975;3(2):159-199.

7. Sharifi GR, Babaei A, Barkhordari A, Faramarzi M, Sadeh M. The effect of one exhausted exercise session on serum serotonin and prolactin level of men runners .occupational Medicine Quarterly journal. 2012; 4 (1,2):53-58

8. Zimmer P, Stritt C, Bloch W, Schmidt F-P, Hübner ST, Binnebößel S, et al. The effects of different aerobic exercise intensities on serum serotonin concentrations and their association with Stroop task performance: a randomized controlled trial. European journal of applied physiology. 2016;116(10):2025-2034.

9. Langfort J, Barańczuk E, Pawlak D, Chalimoniuk M, Lukačova N, Maršala J, et al. The effect of endurance training on regional serotonin metabolism in the brain during early stage of detraining period in the female rat. Cellular and molecular neurobiology. 2006;26(7-8):1325-1340.

10.Ohta M, Hirai N, Ono Y, Ohara M, Saito S, Horiguchi S, et al. Clinical biochemical evaluation of central fatigue with 24hour continuous exercise. Rinsho byori The Japanese journal of clinical pathology. 2005;53(9):802-809.

11.Kirby LG, Chou-Green JM, Davis K, Lucki I. The effects of different stressors on extracellular 5-hydroxytryptamine and 5-hydroxyindoleacetic acid. Brain research. 1997;760(1):218-230.

12.Lemley K. Does Plasma ß-Endorphin Influence ExerciseInduced Hypoalgesia in Healthy Adults? 2009.

13.Kraemer WJ, Dziados JE, Marchitelli LJ, Gordon SE, Harman EA, Mello R, et al. Effects of different heavy-resistance exercise protocols on plasma beta-endorphin concentrations. Journal of Applied Physiology. 1993;74(1):450-459.

14.Walberg-Rankin J, Franke W, Gwazdauskas F. Response of beta-endorphin and estradiol to resistance exercise in females during energy balance and energy restriction. International journal of sports medicine. 1992;13(07):542-547.

15.Goldfarb AH, Jamurtas AZ. $\beta$-Endorphin response to exercise. Sports Medicine. 1997;24(1):8-16.

16.Hackney AC. Exercise as a stressor to the human neuroendocrine system. Medicina (Kaunas). 2006;42(10):788-797.
17.Fazio E MP, Aronica V, Grasso L, Ferlazzo A. Circulating $\beta$-endorphin, adrenocorticotrophic hormone and cortisol levels of stallions before and after short road transport: stress effect of different distances. Acta Veterinaria Scandinavica. 2008;50(1):6-12.

18.Bender T, Nagy G, Barna I, Tefner I, Kádas É, Géher P. The effect of physical therapy on beta-endorphin levels. European journal of applied physiology. 2007;100(4):371-382.

19.Di Luigi L, Guidetti L, Baldari C, Romanelli F. Heredity and pituitary response to exercise-related stress in trained men. International journal of sports medicine. 2003;24(08):551-8.

20.Øktedalen O SE, Haugen AH, Opstad PK. The influence of physical and mental training on plasma beta-endorphin level and pain perception after intensive physical exercise. Stress \& Health. 2001;17(2):6.

21.Jamurtas AZ, Tofas T, Fatouros I, Nikolaidis MG, Paschalis $\mathrm{V}$, Y fanti $\mathrm{C}$, et al. The effects of low and high glycemic index foods on exercise performance and beta-endorphin responses. Journal of the International Society of Sports Nutrition. 2011;8(1):15-22.

22.Koseoglu E AA, Soyuer A, Ersoy O. Aerobic exercise and plasma beta endorphin levels in patients with migrainous headache without aura. Neurology. 2003;23(7):4-10.

23.Zhao J, Lai L, Cheung SS, Cui S, An N, Feng W, et al. Hot environments decrease exercise capacity and elevate multiple neurotransmitters. Life sciences. 2015;141:74-80.

24. Sheikholeslami Vatani D, Salavati, R. The Effects of Obesity and Resistance Exercise Order on Fatigue. Sport Biosciences. 2015;7(1):109-21.

25.Correia PR, Pansani A, Machado F, Andrade M, Silva ACd, Scorza FA, et al. Acute strength exercise and the involvement of small or large muscle mass on plasma brain-derived neurotrophic factor levels. Clinics. 2010;65(11):1123-6.

26. Vega SR, Strüder HK, Wahrmann BV, Schmidt A, Bloch W, Hollmann W. Acute BDNF and cortisol response to low intensity exercise and following ramp incremental exercise to exhaustion in humans. Brain research. 2006;1121(1):5965.

27.Peake JM, Tan SJ, Markworth JF, Broadbent JA, Skinner TL, Cameron-Smith D. Metabolic and hormonal responses to isoenergetic high-intensity interval exercise and continuous moderate-intensity exercise. American Journal of PhysiologyEndocrinology and Metabolism. 2014;307(7):E539-E52.

28.Gómez-Pinilla F, Ying Z, Opazo P, Roy R, Edgerton V. Differential regulation by exercise of BDNF and NT-3 in rat spinal cord and skeletal muscle. European Journal of Neuroscience. 2001;13(6):1078-84.

29. Matthews V, Åström M-B, Chan M, Bruce C, Krabbe K, Prelovsek $\mathrm{O}$, et al. Brain-derived neurotrophic factor is produced by skeletal muscle cells in response to contraction and enhances fat oxidation via activation of AMP-activated protein kinase. Diabetologia. 2009;52(7):1409-18.

30.Heijnen S, Hommel B, Kibele A, Colzato LS. Neuromodulation of Aerobic Exercise-A Review. Frontiers in Psychology, 2016;6. doi:10.3389/fpsyg.2015.01890 
Information about the authors:

Sharifi M.; Graduated Ph.D. in Sport Physiology; (Corresponding author); http://orcid.org/0000-0002-6605-0241; sharifi.moslem@ yahoo.com; Department of Sport Physiology, Faculty of Sport Sciences, Hakim Sabzevari University; Sabzevar, Khorasan Razavi Province, Iran.

Hamedinia M.R.; Professor; https://orcid.org/0000-0002-0973-0435; mrhamedi1350@gmail.com; Department of Sport Physiology, Faculty of Sport Sciences, Hakim Sabzevari University; Sabzevar, Khorasan Razavi Province, Iran.

Hosseini-Kakhak S.A.; Associate Professor; http://orcid.org/0000-0002-7510-2445; sa.hosseini@hsu.ac.ir; Department of Sport Physiology, Faculty of Sport Sciences, Hakim Sabzevari University; Sabzevar, Khorasan Razavi Province, Iran.

Cite this article as: Sharifi M, Hamedinia MR, Hosseini-Kakhak SA. The effect of an exhaustive aerobic, anaerobic and resistance exercise on serotonin, beta-endorphin and BDNF in students. Physical education of students, 2018;22(5):272-277. doi:10.15561/20755279.2018.0507

The electronic version of this article is the complete one and can be found online at: http://www.sportedu.org.ua/index.php/PES/issue/archive

This is an Open Access article distributed under the terms of the Creative Commons Attribution License, which permits unrestricted use, distribution, and reproduction in any medium, provided the original work is properly cited (http://creativecommons.org/licenses/by/4.0/deed.en).

Received: 08.08.2018

Accepted: 03.09.2018; Published: 30.09.2018 